\title{
Toward an anti-inflammatory strategy for depression
}

\author{
Shawn Hayley* \\ Department of Neuroscience, Carleton University, Ottawa, ON, Canada
}

\author{
Edited by: \\ Nuno Sousa, University of Minho, \\ Portugal \\ Reviewed by: \\ Tracy L. Bale, University of \\ Pennsylvania, USA \\ Ronald S. Duman, Yale University \\ School of Medicine, USA \\ ${ }^{*}$ Correspondence: \\ Shawn Hayley, Department of \\ Neuroscience, Carleton University, \\ Room 327, Life Sciences Research \\ Building, 1125 Colonel By Drive, \\ Ottawa, ON, Canada K1S 5B6. \\ e-mail: shayley@ccs.carleton.ca
}

\begin{abstract}
It has become clear that the inflammatory immune system is altered during the course of clinical depression. In particular, studies on human patients have found depression to be associated with disturbances in the trafficking of cells of the adaptive immune system, coupled with elevations of innate immune messengers and pro-inflammatory cytokines. Paralleling these findings, stressor-based animal models of depression have implicated several cytokines, most notably interleukin-1 $\beta$ (IL-1 $\beta$ ), IL-6, and tumor necrosis factor- $\alpha$. Elevations of these cytokines and general inflammatory indicators, such as $\mathrm{C}$-reactive protein, together with reductions of specific immune cells (e.g., T lymphocytes) might serve as useful biomarkers of depression or at least, certain subtypes of the disorder. Recent reports also suggest the possibility that antiinflammatory agents could have therapeutic value in acting as adjunct treatments with traditional anti-depressants. Along these lines, we presently discuss the evidence for pro-inflammatory cytokine involvement in depression, as well as the possibility that anti-inflammatory agents and trophic cytokines themselves might have important anti-depressant properties.
\end{abstract}

Keywords: cytokine, depression, inflammatory, anhedonia, neurogenesis

\section{BACKGROUND}

It has become clear that cells of the immune system can affect the brain and a host of behavioral processes (Blalock, 1984). For instance, it is now accepted that circulating $\mathrm{T}$ lymphocytes and other peripheral immune cells routinely enter the central nervous system (CNS), albeit in limited concentrations, and perform a variety of "housekeeping" tasks that are essential for immunosurveillance. The converse is also true, psychological stressors (which induce neurotransmitter changes) have been demonstrated to disturb functioning of cells of the adaptive immune system, including $\mathrm{T}$ and B lymphocytes, as well as innate immune cells, particularly natural killer (NK) cells and macrophages (Griffiths et al., 2000).

It should be underscored that the blood-brain barrier (BBB), as well as endogenous inhibitory and apoptotic mechanisms within the brain normally tightly regulate the flow of immune factors into and how long they persist within the brain. However, increasing evidence indicates that a range of neurological diseases, including multiple sclerosis, Alzheimer's and Parkinson's disease have a prominent neuroinflammatory component, involving some degree of immune cell infiltration, coupled with activation of brain glial cells (Cotter et al., 1999; Czlonkowska et al., 2002; Wheeler and Owens, 2005).

In addition to the entry of immune cells into the brain parenchyma, substantial evidence has revealed that immune factors can influence CNS functioning through activation of receptors located on peripheral organs or the BBB (Goehler et al., 2006). Indeed, one of the primary mechanisms facilitating neuro-immune communication is the release of soluble low molecular weight glycoprotein messengers called cytokines. Cytokines can bind their receptors located on organs, such as the liver or spleen or the nodose ganglion and trigger the firing of neural fibers from these sites, which then signal the CNS (Cunningham and De Souza, 1993). Cytokines can also interact with BBB receptors to induce cyclooxygenase-2 (COX-2) inflammatory signaling within the brain parenchyma (Rivest, 2001; Hayley et al., 2008).
Although cytokines are normally produced by peripheral immune cells, evidence in recent decades has also convincingly uncovered their production from CNS glial cells (Buttini and Boddeke, 1995). In particular, the immunocompetent, microglia, produce several cytokines and bear receptors for these immunotransmitters, which can act locally in an autocrine or paracrine manner to regular functioning of the original or neighboring cells, respectively (Benveniste, 1992).

Perhaps one of the most intriguing findings in recent years has been that cytokines can markedly affect neurotransmission within emotion regulatory brain circuits, and can induce hormonal changes akin to those normally observed following stressor exposure (Herman and Cullinan, 1997; Hayley et al., 2005). Moreover, numerous studies have implicated cytokines in the genesis of clinical depression and anxiety disorders. To this end, the current perspective review will focus upon evidence that neuro-immune interactions involving peripheral and glial derived cytokines play an important role in depression. Particular attention will be devoted to understanding the mechanisms through which inflammatory cytokines can affect brain processes to cause depressive symptoms and how novel treatment strategies could be developed based on these findings.

\section{INFLAMMATORY/IMMUNE CHANGES IN DEPRESSION}

Owing to the intimate relationship between stressor exposure and the onset of depression, virtually all-animal models of the disorder involve administration of some degree of stress. In general, acute and chronic stressor exposure has been demonstrated to alter adaptive $\mathrm{T}$ and $\mathrm{B}$ lymphocyte proliferative responses and impair certain aspects of innate immunity, most notably NK cell activity (Maes, 1999). Not surprisingly then, clinical depression is also associated with some degree of disturbed immunological responding, along with increased levels of prostaglandin and corticoid hormones, as well as complement and positive acute phase proteins (Miller et al., 2002; Dantzer, 2006). 
Pro-inflammatory cytokine release has been reported to be increased in stressed animals and in depressed individuals. Indeed, elevations of circulating interleukin-1 $\beta$ (IL-1 $\beta$ ), IL-2, IL-6, and interferon- $\gamma$ (IFN- $\gamma$ ) have reported in major depression (Maes, 1999). However, some reported reductions of IL-2 production occurred with depression and were related to peripheral norepinephrine levels but not depressed mood per se (Anisman et al., 1999). Interestingly, dysthymia (chronic low grade depression) was actually associated with greater reductions in mitogen induced lymphocyte proliferation and elevations of circulating IL-1 $\beta$ compared to major depression (Anisman et al., 1999; Zaharia et al., 2000). Similarly, dysthymic children/adolescents were reported to display elevated IL- $1 \beta$ but reduced tumor necrosis factor- $\alpha$ (TNF$\alpha)$ plasma concentrations, whereas those with major depression showed no such changes (Brambilla et al., 2004).

There have been indications that the elevated systemic levels of IL- $1 \beta$, IL- 6 , TNF- $\alpha$, and IFN- $\gamma$ normalized with anti-depressant administration (Basterzi et al., 2005; Tsao et al., 2006). Yet, the elevated production of IL-6, IL-10, and the soluble IL-6 receptor in severe depression (Sluzewska et al., 1995; Maes, 1999) and the elevated IL-1 $\beta$ associated with dysthymia (Griffiths et al., 2000) were not attenuated with anti-depressant treatments. It might be the degree of clinical efficacy achieved that influences cytokine levels since elevated IL- 6 and TNF- $\alpha$ plasma levels in depressed subjects diminished in parallel with a successful anti-depressant response (either with an SSRI or SNRI anti-depressant) (Yoshimura et al., 2009). Further, elevations of cerebrospinal fluid IL-6 levels correlated with depressive symptom severity (being most pronounced in suicide attempters (Lindqvist et al., 2009).

It is important to note that although many significant cytokine differences have been reported, substantial variability exists in cytokine levels normally apparent in clinical populations. Consequently, some researchers (e.g., Kubera et al., 2000; Huang and Lee, 2007) not surprisingly have failed to identify differences in cytokines that others report altered in depression (e.g., IL-1 $\beta$ ). Yet, the pro-inflammatory cytokines, IL-1 $\beta$, IL-6, and TNF- $\alpha$ have generally emerged from the literature as important players in depression. Indeed, one recent metaanalysis that assessed 24 cytokine studies involving patients meeting DSM criteria for depression revealed elevated levels of IL- 6 and TNF- $\alpha$, yet levels of IL-1 $\beta$, IL-2, IL-4, IL-8, IL-10, and IFN $-\gamma$ were not significantly affected (Dowlati et al., 2010). A second meta-analysis further reported that IL-1 $\beta$, IL- 6 , and the inflammatory marker, C-reactive protein (which is important in cardiac illness) were likewise positively associated with depression (Howren et al., 2009).

Although the data are particularly scant, a few recent postmortem studies have assessed brain cytokine variations in depressed individuals that died from suicide. These have revealed some statistically significant (albeit modest) cytokine variations in stressorsensitive limbic brain regions. For instance, the mRNA for the type 2 T helper cytokines, IL-4 and IL-13, were elevated in a genderdependent manner (IL-4 in females and IL-13 in males) in the orbitofrontal cortex of depressed suicides (Tonelli et al., 2008). Similarly, TNF- $\alpha$ was increased within the left hemisphere of the dorsolateral prefrontal cortex (PFC) of individuals that suffered from major depression (Dean et al., 2010).
Although CNS cytokine elevations in depression could stem, in part, from peripheral sources, brain glia are also very likely contributors. Along these lines, a reduction in the number of glia was apparent within the amygdala, anterior cingulate cortex (ACC) and PFC of individuals with major depression (Bowley et al., 2002; Cotter et al., 2002). Further studies confirmed a reduction in expression of the astrocyte marker, GFAP, in postmortem brain tissue from depressed subjects (Webster et al., 2005). Parallel animal studies likewise revealed reductions in hippocampal GFAP following stressor exposure that correlated with depressive-like behaviors (Liu et al., 2009). This is important in light of the fact that astrocytes are primary producers of the trophic factor, brain-derived neurotrophic factor (BDNF), which has also been reported to be reduced in the human depressed brain and in animal stressor models (Duman et al., 1999; Shirayama et al., 2002; Musazzi et al., 2009).

In contrast to the astrocyte reduction, an increased density of microglial cells was reported within the ACC and PFC of depressed individuals that committed suicide; yet, schizophrenic suicides also showed such an effect (Steiner et al., 2008). Hence, it might be some aspect of the suicidal behavior itself that contributed to the microgliosis. In fact, the profile of circulating cytokines was found to differ in suicide attempters compared to non-suicidal depressed patients, with the former group showing greater IL- 6 and TNF- $\alpha$ elevations, coupled with IL-2 reductions (Janelidze et al., 2010). Nonetheless, it is informative that animal studies reported elevated microglial density and morphological changes following stressor exposure (Tynan et al., 2010). Ultimately, one could speculate that stressors favor diminished plasticity and neurochemical changes aligned with depressive pathology by reducing astrocyte trophic responses, while concomitantly augmenting microglial production of pro-inflammatory and oxidative factors.

\section{CYTOKINE-STRESS INVOLVEMENT AND DEPRESSION}

When considering the involvement of cytokines in depression it is important to point out the likelihood that cytokines are important for a subset but not all depressive symptoms. In this regard, cytokines have potent sickness inducing effects, which are often taken to reflect some form of depression (Anisman et al., 2008; Dantzer et al., 2008). While it is certainly reasonable that many aspects of sickness, such as the lethargy and "flu-like" symptoms, do resemble some of the more vegetative aspects of depression, the profound melancholia is harder to model in animals and might be somewhat independent from cytokine effects. Thus, it may be useful to view cytokines as being only one potentially very important trigger that acts together with psychosocial challenges to provoke the manifestation and evolution of the disorder.

\section{CYTOKINE-STRESS CONNECTION}

Administration of IL-1 $\beta$ or TNF- $\alpha$, typically engender an array of behavioral symptoms (soporific effects, ptosis, anorexia, fever, fatigue, reduced motor activity, curled body posture) referred to as "sickness behaviors" (Hayley et al., 1999; Dantzer et al., 2008). Similarly, these same cytokines also have potent activating effects on the hypothalamic-pituitary-adrenal (HPA) axis and promote increased monoamine utilization in numerous brain regions (Dunn, 2006; Anisman et al., 2008). Importantly, at least some of the behavioral consequences appear to be mediated, in part, by 
central mechanisms, as low doses of IL- $1 \beta$ or TNF- $\alpha$ administered directly into the brain elicited these behaviors (Maier et al., 1999; Konsman et al., 2002). The behavioral and neurochemical impact of IL-6, although similar in profile, is somewhat less pronounced than that of IL-1 $\beta$ or TNF- $\alpha$ (Dunn et al., 1999; Brebner et al., 2000; Hayley et al., 2005). However, the cytokine normally requires its endogenous soluble receptor ligand for its full range of biological effects (in contrast to the endogenous IL- $1 \beta$ and TNF- $\alpha$ soluble antagonists, the IL-6 soluble receptor acts as an agonist) and hence, exogenous IL-6 alone might have moderate CNS effects.

It is highly likely that the effects of cytokines are intermingled with the impact of the daily stressors that one normally faces. In this regard, it is important to note that social stressors were reported to augment the impact of immunological challenges on CNS functioning (Avitsur et al., 2005; Gibb et al., 2008). For instance, we previously found that when mice were subjected to a psychosocial stressor (disruption of social housing), they displayed greatly augmented behavioral changes and HPA activation to concomitant or subsequent immune (LPS, poly I:C) or cytokine (interferon- $\alpha$ ) challenge (Anisman et al., 2007; Gandhi et al., 2007; Gibb et al., 2008). Interestingly, the bacterial mimic, LPS, but not the viral analog, poly I:C, synergistically increased the impact of the social stressor upon sickness and plasma corticosterone levels. Moreover, LPS also interacted with the social stress to additively or synergistically enhance CNS mRNA for the cytokines IL-6, IL-10, and TNF- $\alpha$ (in a brain region and cytokine specific manner; Gibb et al., 2011).

The fact that many of the CNS effects of cytokine and stressor exposure were strain-dependent is of importance given that genetic vulnerability likely contributes to stressor sensitivity and hence, depressive illness. Indeed, the behavioral and HPA variations induced by stressor + LPS treatments appeared to be more pronounced in BALB/cByJ mice (which were previously reported to be a "stressor sensitive" strain), compared to the more "stressor hardy" C57BL/6ByJ strain (Gibb et al., 2011). Yet, the fact that elevations in circulating and central cytokines were greater in the C57BL/6ByJ strain suggests that the role of genetics and cytokine signaling is probably quite complex.

In terms of potential signaling CNS pathways that might subserve the common effects of cytokines and stressors, recent studies have revealed that IL-1 $\beta$ and its downstream transcription factor, NFkB, are important mediators of the anti-neurogenic and depressive-like effects of acute and chronic stressor exposure. Specifically, pharmacological or genetic inhibition of either IL- $1 \beta$ or NFkB prevented the depressive-like behavioral changes (reduced mobility in a forced swim test and reduced consumption of a sucrose solution) and reduction of hippocampal neurogenesis normally provoked by acute restraint or repeated exposure a series of different mild stressors (Koo and Duman, 2008; Koo et al., 2010). Interestingly, NFKB mediated signaling following Toll-like receptor (TLR) activation was also reported to be influenced by psychosocial stressors (Bailey et al., 2007), raising the possibility that this signaling pathway might be especially sensitive to the impact of both immune and psychological challenges.

\section{INTERFERONS}

Given their potent anti-viral and anti-tumor effects that have resulted in widespread clinical use, coupled with their numerous CNS effects, IFNs might be particularly important with regards to neuropsychi- atric pathology. Indeed, IFN- $\alpha$ (and IL-2 in earlier studies), which is often used as a therapeutic treatment for certain cancers and hepatitis C, has been reported to cause a depressive syndrome (as well as irritability, anxiety, and cognitive problems) amenable to anti-depressant treatment (Denicoff et al., 1987; Dieperink et al., 2003; Constant et al., 2005; Raison et al., 2005). It is also important to note that the cancer and hepatitis $\mathrm{C}$ patients are undoubtedly under considerable emotional distress, and hence, the impact of IFN- $\alpha$ would be expected to be augmented by the concomitant stressor exposure, as we previously reported for mice exposed to the cytokine in the context of a psychosocial stressor (Anisman et al., 2007).

Animal studies revealed that rodents treated with IFN- $\alpha$ displayed marked signs of anhedonia, impaired hippocampal neurogenesis and a reduction of cortical neuronal fiber density (Kaneko et al., 2006; Ishikawa et al., 2007). Some studies also report that systemic IFN- $\alpha$ administration induced neurochemical changes (5-HT and NE in several brain regions) in rodents (Anisman et al., 2007), as well as in rhesus monkeys (altered CSF DA metabolite, along with IL-6 and HPA hormones, coupled with reduced exploration and huddling behaviors; Felger et al., 2007).

Many anti-depressants, including fluoxetine, trimipramine, and reboxetine, either suppress IFN- $\gamma$ production or reduce the IFN- $\gamma /$ IL-10 ratio (Diamond et al., 2006). Consistent with these findings, anti-depressant treatment was shown to normalize the otherwise high levels of IFN- $\gamma$ expression observed in depressed patients (Kubera et al., 2001). Similarly, genetic knockout of the IFN- $\gamma$ receptor prevented the depressive-like effects of Bacillus Calmette-Guerin infection in mice (a model of immune-mediated depression; O'Connor et al., 2009a).

The depressive-like effects of IFN- $\alpha$ as well as other pro-inflammatory cytokines, including IL- $1 \beta$ and IFN- $\gamma$, have been suggested to stem from the ability of these cytokines to affect the enzyme, indoleamine 2,3-dioxygenase (IDO), which is responsible for the catabolism of tryptophan to kynurenine (Hu et al., 1995; Menkes and MacDonald, 2000; Capuron et al., 2003; O'Connor et al., 2009b). Essentially, tryptophan can be metabolized to 5-HT or be affected sequentially by the enzymes, ATP bind cassette and IDO, resulting in the production of kynurenine, which can further follow two different metabolic routes resulting in production of: (1) the NMDA antagonist, kynurenic acid, or (2) the potentially toxic metabolites, 3-hydroxykynurenine and quinolinic acid.

The potential importance of the tryptophan-kynurenine pathway in depression was first proposed by Mangoni (1974) and later expanded upon by Myint and Kim (2003) with subsequent in vitro and in vivo experiments demonstrated that IFN- $\alpha$ did alter IDO activity and reduce 5-HT levels (Myint et al., 2007). In fact, reduced tryptophan and increased levels of toxic kynurenine metabolites correlated with the depressive symptoms observed in hepatitis $\mathrm{C}$ patients treated with IFN- $\alpha$ (Bonaccorso et al., 2002; Raison et al., 2010). Besides being increased with depression, these kynurenine metabolites (3-hydroxykynurenine and quinolinic acid) have neurotoxic effects and have been reported to synergistically induce free radicals in several neurodegenerative diseases (Wichers and Maes, 2004; Hartai et al., 2005; Wichers et al., 2005). Ultimately, an imbalance in tryptophan metabolism that favors activation of the kynurenine-quinolinc acid pathway could foster depressive pathology through: (1) a reduction in available 5-HT and (2) accumulation of toxic metabolites. 


\section{TOWARD AN ANTI-INFLAMMATORY/NEUROTROPHIC TREATMENT STRATEGY}

Many broad-spectrum anti-inflammatory agents presently are available for a controlling fever, pain, and edema for a range of peripheral immune related conditions. Importantly, many of these compounds have also been shown to have beneficial CNS effects, including having neuroprotective effects in animal models of cerebral stroke, Alzheimer's and Parkinson's disease (Teismann et al., 2003; Phillis et al., 2006). Moreover, some scattered preclinical and stressor-based animal studies suggest that non-steroidal anti-inflammatory drugs (NSAIDS), including aspirin, ibuprofen, celecoxib, and naproxen might possibly have some anti-depressant properties (Müller et al., 2006; Müller and Schwarz, 2008). These drugs typically work by blocking cyclooxygenases, which of course are the rate-limiting enzymes (COX-1, -2 , and -3 present in the CNS) in prostaglandin synthesis. COX-2 is subject to induction by a variety of inflammatory stimuli, many of which (e.g., cytokines) have been implicated in the generalized activation of microglial cells in response to and as a corollary of brain injury and infection (Hayley et al., 2008).

One recent study found that celecoxib alleviated the depressivelike behaviors and prevented the COX-2 elevations associated with 21 days of chronic stress (Guo et al., 2009). Similarly, administration of celecoxib augmented the clinical impact of the anti-depressant, fluoxetine (Akhondzadeh et al., 2009). This important finding suggests the possibility that anti-inflammatory drugs might be useful adjunct or "add-on" treatments, which could act additively or synergistically with SSRI or SNRI anti-depressants to bolster the clinical efficacy.

Mechanistically, NSAIDs could contribute anti-depressant-like effects by blocking COX-2 activity, since this inflammatory enzyme, along with its associated products, prostaglandins and kynurenine, have been associated with depression (Müller and Schwarz, 2008). Moreover, the immune alterations that likely occur with depression have been reported to alter tryptophan/kynurenine metabolism, favoring the neurotoxic effects of quinolinic acid (Wichers and Maes, 2004). Of course, the possibility exists that COX-signaling could also influence depressive symptoms by affecting hormonal activity. Indeed, aspirin was reported to reduce waking cortisol levels and improve memory in depressed subjects (Watson et al., 2009).

Another compound of significance is the tetracycline antibiotic, minocycline, which has potent anti-inflammatory effects (including a suppression of microglial activity) that are independent of its antimicrobial actions (Pae et al., 2008). Recently, brain infusion (into the nucleus accumbens) or systemic administration of minocycline was shown to impart anti-depressive-like effects in the forced swim test. Moreover, co-administration of minocycline with the SSRI anti-depressant, fluoxetine, induced a synergistic anti-depressive effect (Molina-Hernández et al., 2008a,b). The antidepressive effects of minocycline could stem from its ability to block IDO activity, resulting in a normalization of the kynurenine/ tryptophan ratio (Myint et al., 2007).

In addition to broad-spectrum pharmacological agents, specific cytokines with anti-inflammatory or neurotrophic properties have been suggested to have clinical anti-depressant properties. For instance, erythropoietin is a cytokine produced predominately by the kidney, which, besides directing the trafficking of immune cells and having anti-apoptotic actions, was reported to provoke anti-depressant-like effects in the forced swim and novelty induced hypophagia tests (Girgenti et al., 2009). This cytokine, as well as related hematopoietic cytokines, including granulocyte colony stimulating factor, might act, in part, through their ability to induce BDNF expression within the CNS.

Central infusion of BDNF (considered a neurotrophic cytokine itself) was shown to induce an anti-depressant-like effect while concomitantly promoting sprouting of central 5-HT neurons (Altar, 1999). Likewise, hippocampal infusion of BDNF produced anti-depressant-like effects in the learned helplessness and forced swim models of depression (Shirayama et al., 2002). As would be expected, several clinically beneficial treatments, including SSRIs, tricyclics, and electroconvulsive therapy, increased hippocampal BDNF expression (Shirayama et al., 2002; Castrén et al., 2007) and the reduced BDNF associated with restraint stress was prevented by anti-depressant treatment (Duman et al., 1999).

Finally, one promising approach to treating the inflammatory aspects of depression is the use of specific cytokine antagonists. In this regard, most evidence would favor targeting IL-1 $\beta$ using the endogenous IL-1 $\beta$ receptor antagonist, IL-1ra. Indeed, IL-1ra was reported in several studies to prevent the development of depressive-like behavioral and neurochemical pathology, as well as the reduction of hippocampal neurogenesis that was induced by chronic stressor exposure (Koo and Duman, 2008; Norman et al., 2010).

\section{CONCLUSIONS AND FUTURE DIRECTIONS}

This review discusses the evidence for involvement of cytokines and their inflammatory signaling components in clinical depression. It is posited that normalization of some of the pro-inflammatory aspects of depression would have beneficial clinical effects. Hence, antiinflammatory agents (e.g., those affecting COX-2 and IDO or targeting specific cytokines, such as IL-1 $\beta$ ) could hold therapeutic potential as add-on or adjunct treatment with more traditional anti-depressant strategies. At the same time, novel cytokines with neurotrophic consequences, particularly BDNF, appear attractive. Indeed, mounting data indicate structural and neuroplastic (e.g., reduced hippocampal volume and neurogenesis) disturbances may occur in depression.

Whatever the case, it is being increasingly recognized that depression is a spectrum disorder with several endophenotypes, which are likely characterized by specific differences in their neurochemistry and underlying inflammatory immunological changes. Hence, first recognizing the nature of immune and cytokine changes in these depressive subtypes is necessary in order to tailor specific interventions. Once brought to the clinical arena, several practical issues require addressing including, bioavailability and CNS penetration of the agents (as cytokines typically do not readily cross the BBB), as well as consideration of the possibility that manipulation of immunity could have drastically undesirable consequences (e.g., increased infection or tumor production). In effect, further data are required to more completely understand the critical inflammatory components to be targeted and the long-term consequences of their manipulation.

\section{ACKNOWLEDGMENTS}

Shawn Hayley is an Associate Professor and Canada Research Chair in Neuroscience. Shawn Hayley research was supported by funds from the Canadian Institutions of Health Research (CIHR), Natural Sciences and Engineering Research Council (NSERC), and National Association for Research of Schizophrenia and Depression (NARSAD). 


\section{REFERENCES}

Akhondzadeh, S., Jafari, S., Raisi, F., Nasehi, A. A., Ghoreishi, A., Salehi, B., Mohebbi-Rasa, S., Raznahan, M., and Kamalipour, A. (2009). Clinical trial of adjunctive celecoxib treatment in patients with major depression: a double blind and placebo controlled trial. Depress. Anxiety 26, 607-611.

Altar, C. A. (1999). Neurotrophins and depression. Trends Pharmacol. Sci. 20, 59-61.

Anisman, H., Gibb, J., and Hayley, S. (2008). Influence of continuous infusion of interleukin-1beta on depression-related processes in mice: corticosterone, circulating cytokines, brain monoamines, and cytokine mRNA expression. Psychopharmacology (Berl.) 199, 231-244

Anisman, H., Poulter, M. O., Gandhi, R., Merail, Z., and Hayley, S. (2007). Interferon-alpha effects are exaggerated when administered on a psychosocial stressor backdrop: cytokine, corticosterone and brain monoamine variations. J. Neuroimmunol. 186, 45-53.

Anisman, H., Ravindran, A.V., Griffiths, J., and Merali, Z. (1999). Endocrine and cytokine correlates of major depression and dysthymia with typical or atypical features. Mol. Psychiatry 4, 182-188.

Avitsur, R., Kavelaars, A., Heijnen, C., and Sheridan, J. F. (2005). Social stress and the regulation of tumor necrosis factor-alpha secretion. Brain Behav. Immun. 19, 311-317.

Bailey, M. T., Engler, H., Powell, N. D., Padgett, D. A., and Sheridan, J. F. (2007). Repeated social defeat increases the bactericidal activity of splenic macrophages through a Tolllike receptor-dependent pathway. Am. J. Physiol. Regul. Integr. Comp. Physiol. 293, R1180-R1190.

Basterzi, A. D., Aydemir, C., Kisa, C., Aksaray. S., Tuzer, V., Yazici, K., and Goka, E. (2005). IL-6 levels decrease with SSRI treatment in patients with major depression. Hum. Psychopharmacol. 20, 473-476.

Benveniste, E. N. (1992). Cytokines: influence on glial cell gene expression and function. Chem. Immunol. $52,106-153$.

Blalock, J.E. (1984). The immune system as a sensory organ. J. Immunol. 132, 1067-1070.

Bonaccorso, S., Puzella, A., Marino, V., Pasquini, M., Biondi, M., Artini, M., Almerighi, C., Levrero, M., Egyed, B., Bosmans, E., Meltzer, H. Y., and Maes, M. (2002). Increased depressive ratings in patients with hepatitis $\mathrm{C}$ receiving interferon-alpha-based immunotherapy are related to interferon-alpha-induced changes in the serotonergic system. J. Clin. Psychopharmacol. 22, 86-90.

Bowley, M. P., Drevets, W. C., Ongür, D., and Price, J. L. (2002). Low glial numbers in the amygdala in major depressive disorder. Biol. Psychiatry $52,404-412$.

Brambilla, F., Monteleone, P., and Maj, M. (2004). Interleukin-1beta and tumor necrosis factor-alpha in children with major depressive disorder or dysthymia. J. Affect. Disord. 78, 273-277.

Brebner, K., Hayley, S., Zarchko, R. Merail, Z., and Anisman, H. (2000). Synergistic effects of interleukin1 beta, interleukin-6, and tumor necrosis factor-alpha: central monoamine, corticosterone, and behavioral variations. Neuropsychopharmacology 22 , 566-580.

Buttini, M., and Boddeke, H. (1995) Peripheral lipopolysaccharide stimulation induces interleukin- $1 \mathrm{~b}$ messenger RNA in rat brain microglial cells. Neuroscience 65, 523-530.

Capuron, L., Neurauter, G., Musselman, D. L., Lawson, D. H., Nemeroff, C. B., Fuchs, D., and Miller, A. H. (2003). Interferon-alpha-induced changes in tryptophan metabolism: relationship to depression and paroxetine treatment. Biol. Psychiatry 54, 906-914.

Castrén, E., Võikar, V., and Rantamäki, T. (2007). Role of neurotrophic factors in depression. Curr. Opin. Pharmacol. 7, 18-121.

Constant, A., Castera, L., Dantzer, R., Couzigou, P., de Ledinghen, V. Demotes-Mainard, J., and Henry, C. (2005). Mood alterations during interferon-alfa therapy in patients with chronic hepatitis $\mathrm{C}$ : evidence for an overlap between manic/hypomanic and depressive symptoms. J. Clin. Psychiatry 66, 1050-1057.

Cotter, D., Mackay, D., Chana, G., Beasley, C., Landau, S., and Everall, I. P. (2002). Reduced neuronal size and glial cell density in area 9 of the dorsolateral prefrontal cortex in subjects with major depressive disorder. Cereb. Cortex 12, 386-394.

Cotter, R. L., Burke, W. J., Thomas, V. S. Potter, J. F., Zheng, J., and Gendelman, H. E. (1999). Insights into the neurodegenerative process of Alzheimer's disease: a role for mononuclear phagocyte-associated inflammation and neurotoxicity. J. Leukoc. Biol. 65, 416-427.

Cunningham, E. T., and De Souza, E. B. (1993). Interleukin 1 receptors in the brain and endocrine tissues. Immunol. Today 14, 171-176.

Czlonkowska, A., Kurkowska-Jastrzebska, I., Czlonkowski, A., Peter, D., and
Stefano, G. (2002). Immune processes in the pathogenesis of Parkinson's disease: a potential role for microglia and nitric oxide. Med. Sci. Monit. 8, 65-77.

Dantzer, R. (2006). Cytokine, sickness behavior, and depression. Neurol. Clin 24, 441-460.

Dantzer, R., O'Connor, J. C., Freund G. G., Johnson, R. W., and Kelley, K. W. (2008). From inflammation to sickness and depression: when the immune system subjugates the brain. Nat. Rev. Neurosci. 9, 46-56.

Dean, B., Tawadros, N., Scarr, E., and Gibbons, AS. (2010). Regionallyspecific changes in levels of tumour necrosis factor in the dorsolateral prefrontal cortex obtained postmortem from subjects with major depressive disorder. J. Affect. Disord. 120, 45-48. Denicoff, K. D., Rubinow, D. R., Papa, M. Z., Simpson, L., Seipp, L. A., Lotze, M. T., Chang, A. E., Rosenstein, D., and Rosenberg, S.A. (1987). The neuropsychiatric effects of treatment with interleukin-2 and lymphokine-activated killer cells. Ann. Int. Med. 107, 293-300.

Diamond, M., Kelly, J. P., and Connor T. J. (2006). Antidepressants suppress production of the Thl cytokine interferon-gamma, independent of monoamine transporter blockade. Eur. Neuropsychopharmacol. 16, 481-490.

Dieperink, E., Ho, S. B., Thuras, P., and Willenbring, M. L. (2003). A prospective study of neuropsychiatric symptoms associated with interferonalpha- $2 b$ and ribavirin therapy for patients with chronic hepatitis $\mathrm{C}$. Psychosomatics 44, 104-112.

Dowlati, Y., Herrmann, N., Swardfager W., Liu, H., Sham, L., Reim, E. K., and Lanctôt, K. L. (2010). A meta-analysis of cytokines in major depression. Biol. Psychiatry 67, 446-457.

Duman, R. S., Malberg, J., and Thome, J. (1999). Neural plasticity to stress and antidepressant treatment. Biol. Psychiatry 46, 1181-1191.

Dunn, A. J. (2006). Effects of cytokines and infections on brain neurochemistry. Clin. Neurosci. Res. 6, 52-68.

Dunn, A. J., Wang, J., and Ando, T. (1999). Effects of cytokines on cerebral neurotransmission. Comparison with the effects of stress. Adv. Exp. Med. Biol. 461 117-127.

Felger, J. C., Alagbe, O., Hu, F., Mook, D., Freeman, A. A., Sanchez, M. M. Kalin, N. H., Ratti, E., Nemeroff, C. B., and Miller, A. H. (2007). Effects of interferon-alpha on rhesus monkeys: a nonhuman primate model of cytokine-induced depression. Biol. Psychiatry 62, 1324-1333.

Gandhi, R., Hayley, S., Gibb, J., Merali, Z., and Anisman, H. (2007). Influence of poly I:C on sickness behaviors, plasma cytokines, corticosterone and central monoamine activity: moderation by social stressors. Brain Behav. Immun. 21, 477-489.

Gibb, J., Hayley, S., Gandhi, R., Poulter, M. O., and Anisman, H. (2008). Synergistic and additive actions of a psychosocial stressor and endotoxin challenge: circulating and brain cytokines, plasma corticosterone and behavioral changes in mice. Brain Behav. Immun. 22, 573-589.

Gibb, J., Hayley, S., Poulter, M. O., and Anisman, H. (2011). Effects of stressors and immune activating agents on peripheral and central cytokines in mouse strains that differ in stressor responsivity. Brain Behav. Immun $25,468-482$.

Girgenti, M. J., Hunberger, J., Duman, C. H., Sathyanesan, M., Terwilliger, R., and Newton, S. S. (2009). Erythropoietin induction by electroconvulsive seizure, gene regulation, and antidepressant-like behavioral effects. Biol. Psych. 66, 267-274.

Goehler, L. E., Erisir, A., and Gaykema, R. P. (2006). Neural-immune interface in he rat area postrema. Neuroscience 140, 1415-1434.

Griffiths, J., Ravindran, A.V., Merali, Z., and Anisman, H. (2000). Dysthymia: neurochemical and behavioral perspectives. Mol. Psychiatry 5, 242-261.

Guo, J.Y., Li, C. Y., Ruan, Y. P., Sun, M., Qi X. L., Zhao, B. S., and Luo, F. (2009). Chronic treatment with celecoxib reverses chronic unpredictable stressinduced depressive-like behavior via reducing cyclooxygenase-2 expression in rat brain. Eur. J. Pharmacol. $612,54-60$

Hartai, Z., Klivenyi, P., Janaky, T., Penke, B., Dux, L., and Vecsei, L. (2005) Kynurenine metabolism in multiple sclerosis. Acta Neurol. Scand. 112 93-96.

Hayley, S., Brebner, K., Lacosta, S., Merali, Z., and Anisman, H. (1999). Sensitization to the effects of tumor necrosis factor-alpha: neuroendocrine, central monoamine, and behavioral variations. J. Neurosci. 19 , 5654-5665.

Hayley, S., Mangano, E., Strickland, M., and Anisman, H. (2008) Lipopolysaccharide and a social stressor influence behaviour, corticosterone and cytokine levels: divergent actions in cyclooxygenase- 2 deficient mice and wild type controls. $J$. Neuroimmunol. 197, 29-36.

Hayley, S., Poulter, M. O., Merali, Z., and Anisman, H. (2005). The pathogenesis of clinical depression: stressorand cytokine-induced alterations of neuroplasticity. Neuroscience 135, $659-678$. 
Herman, J. P., and Cullinan, W. E. (1997). Neurocircuitry of stress: central control of hypothalamo-pituitaryadrenocortical axis. Trends Neurosci. 20, 78-84.

Howren, M. B., Lamkin, D. M., and Suls, J. (2009). Associations of depression with C-reactive protein, IL-1, and IL-6: a meta-analysis. Psychosom. Med. 71, 171-186.

Hu, B., Hissong, B. D., and Carlin, J. M. (1995). Interleukin-1 enhances indoleamine 2,3-dioxygenase activity by increasing specific mRNA expression in human mononuclear phagocytes. J. Interferon Cytokine Res. 15, 617-624.

Huang, T. L., and Lee, C. T. (2007). T-helper 1/T-helper 2 cytokine imbalance and clinical phenotypes of acutephase major depression. Psychiatry Clin. Neurosci. 61, 415-420.

Ishikawa, J., Ishikawa, A., and Nakamura, S. (2007). Interferon-alpha reduces the density of monoaminergic axons in the rat brain. Neuroreport 18, 137-140.

Janelidze, S., Mattei, D., Westrin, S., Träskman-Bendz, L., and Brundin, L. (2010). Cytokine levels in the blood may distinguish suicide attempters from depressed patients. Brain Behav. Immun. doi: 10.1016/j.bbi.2010.10.010. [Epub ahead of print].

Kaneko, N., Kudo, K., Mabuchi, T, Takemoto, K., Fujimaki, K., Wati, H., Iguchi, H., Tezuka, H., and Kanba, S. (2006). Suppression of cell proliferation by interferon-alpha through interleukin-1 production in adult rat dentate gyrus. Neuropsychopharmacology 31, 2619-2626.

Konsman, J. P., Parnet, P., and Dantzer, R. (2002). Cytokine-induced sickness behaviour: mechanisms and implications. Trends Neurosci. 25, 154-159.

Koo, J. W., and Duman, R. S. (2008). IL-1beta is an essential mediator of the antineurogenic and anhedonic effects of stress. Proc. Natl. Acad. Sci. U.S.A. 105,751-756.

Koo, J. W., Russo, S. J., Ferguson, D., Nestler, E. J., and Duman, R. S. (2010). Nuclear factor-kappaB is a critical mediator of stress-impaired neurogenesis and depressive behavior. Proc. Natl. Acad. Sci. U.S.A. 107, 2669-2674.

Kubera, M., Kenis, G., Bosmans, E., Zieba, A., Dudek, D., Nowak, G., and Maes, M. (2000). Plasma levels of interleukin-6, interleukin-10, and interleukin-1 receptor antagonist in depression: comparison between the acute state and after remission. Pol. J. Pharmacol. 52, 237-241.

Kubera, M., Lin, A.H., Kenis, G., Bosmans, E., van Bockstaele, D., and Maes, M. (2001). Anti-inflammatory effects of antidepressants through suppres- sion of the interferon-gamma/interleukin-10 production ratio. J. Clin. Psychopharmacol. 21, 199-206.

Lindqvist, D., Janelidze, S., Hagell, P., Erhardt, S., Samuelsson, M., Minthon, L., Hansson, O., Björkqvist, M., Träskman-Bendz, L., and Brundin, L. (2009). Interleukin-6 is elevated in the cerebrospinal fluid of suicide attempters and related to symptom severity. Biol. Psychiatry 66, 287-292.

Liu, Q., Li, B., Zhu, H. Y., Wang, Y. Q., Yu, J., and Wu, G. C. (2009). Clomipramine treatment reversed the glial pathology in a chronic unpredictable stressinduced rat model of depression. Eur. Neuropsychopharmacol. 19, 796-805.

Maes, M. (1999). Major depression and activation of the inflammatory response system. Adv. Exp. Med. Biol. 461, 25-45.

Maier, S. F., Nguyen, K. T., Deak, T., Milligan, E. D., and Watkins, L. R. (1999). Stress, learned helplessness, and brain interleukin-1 beta. $A d v$. Exp. Med. Biol. 461, 235-249.

Mangoni, A. (1974). The "kynurenine shunt" and depression. Adv. Biochem. Psychopharmacol. 11, 293-298.

Menkes, D. B., and MacDonald, J. A. (2000). Interferons, serotonin and neurotoxicity. Psychol. Med. 30, 259-268.

Miller, G. E., Stetler, C. A., Carney, R. M., Freedland, K. E., and Banks, W. A. (2002). Clinical depression and inflammatory risk markers for coronary heart disease. Am. J. Cardiol. 90, 1279-1283.

Molina-Hernández, M., Tellez-Alcántara, N. P., Pérez-García, J., OliveraLopez, J. I., and Jaramillo-Jaimes, M. T. (2008a). Antidepressant-like actions of minocycline combined with several glutamate antagonists. Prog. Neuropsychopharmacol. Biol. Psychiatry 32, 380-386.

Molina-Hernández, M., TéllezAlcántara, N. P., Pérez-García, J., Olivera-Lopez, J. I., and JaramilloJaimes, M. T. (2008b). Desipramine or glutamate antagonists synergized the antidepressant-like actions of intra-nucleus accumbens infusions of minocycline in male Wistar rats. Prog. Neuropsychopharmacol. Biol. Psychiatry 32, 1660-1666.

Müller, N., and Schwarz, M. J. (2008). COX-2 inhibition in schizophrenia and major depression. Curr. Pharm. Des. 14, 1452-1465.

Müller, N., Schwarz, M. J., Dehning S, Douhe, A., Certovecki, A., GoldsteinMuller, B., Spellman, I., Hetzel, G., Maino, K., Kleindienst, N, Moller, $\mathrm{H}$. J., Arolt, V., and Ridel, M. (2006). The cyclooxygenase-2 inhibitor celecoxib has therapeutic effects in major depression: results of a double-blind, randomized, placebo controlled, addon pilot study to reboxetine. $\mathrm{Mol}$. Psychiatry 11, 680-684.

Musazzi, L., Cattaneo, A., Tardito, D, Barbon, A., Gennarelli, M., Barlati, S., Racagni, G., and Popoli, M. (2009). Early raise of BDNF in hippocampus suggests induction of posttranscriptional mechanisms by antidepressants. BMC Neurosci. 10, 48. doi: 10.1186/1471-2202-10-48

Myint, A. M., and Kim, T. K. (2003). Cytokine-serotonin interaction through IDO: a neurodegeneration hypothesis of depression. Med. Hypotheses 61, 519-525.

Myint, A. M., Kim, Y. K., Verkerk, R., Scharpe, S., Steinbusch, H., and Leonard, B. E. (2007). Kynurenine pathway in major depression: evidence of impaired neuroprotection. J. Affect. Disord. 98, 143-151.

Norman, G. J., Karelina, K., Zhang, N., Walton, J. C., Morris, J. S., and Devries, A. C. (2010). Stress and IL-1beta contribute to the development of depressive-like behavior following peripheral nerve injury. Mol. Psychiatry 15, 404-414.

O'Connor, J. C., André, C., Wang, Y. Lawson, M. A., Szegedi, S. S., Lestage, J., Castanon, N., Kelley, K. W., and Dantzer, R. (2009a). Interferon-gamma and tumor necrosis factor-alpha mediate the upregulation of indoleamine 2,3-dioxygenase and the induction of depressive-like behavior in mice in response to bacillus Calmette-Guerin. J. Neurosci. 29, 4200-4209.

O’Connor, J. C., Lawson, M. A., André, C., Moreau, M., Lestage, J., Castanon, N., Kelley, K. W., and Dantzer, R. (2009b).Lipopolysaccharide-induced depressive-like behavior is mediated by indoleamine 2,3-dioxygenase activation in mice. Mol. Psychiatry 14, 511-522.

Pae, C. U., Marks, D. M., Han, C., and Patkar, A.A. (2008). Does minocycline have antidepressant effect? Biomed. Pharmacother. 62, 308-311.

Phillis, J. W., Horrocks, L. A., and Farooqui, A.A. (2006). Cyclooxygenases, lipoxygenases, and epoxygenases in CNS: their role and involvement in neurological disorders. Brain Res. Rev. 52, 201-243.

Raison, C. L., Dantzer, R., Kelley, K. W. Lawson, M. A., Woolwine, B. J., Vogt, G., Spivey, J. R., Saito, K., and Miller, A. H. (2010). CSF concentrations of brain tryptophan and kynurenines during immune stimulation with IFN-alpha: relationship to CNS immune responses and depression. Mol. Psychiatry 15, 393-403.

Raison, C. L., Demetrashvili, M., Capuron, L., and Miller, A. H. (2005)
Neuropsychiatric adverse effects of interferon-alpha: recognition and management. CNS Drugs 19, 105-123.

Rivest,S. (2001). How circulating cytokines trigger the neural circuits that control the hypothalamic-pituitary-adrenal axis. Psychoneuroendocrinology 26, 761-788.

Shirayama, Y., Chen, A. C., Nakagawa, S., Russell, D. S., and Duman, R. S. (2002). Brain-derived neurotrophic factor produces antidepressant effects in behavioral models of depression. J. Neurosci. 22, 3251-3261.

Sluzewska, A., Rybakowski, J. K., Laciak, M., Mackiewicz, A., Sobieska, M., and Wiktorowicz, K. (1995). Interleukin-6 serum levels in depressed patients before and after treatment with fluoxetine. Ann. N.Y. Acad. Sci. 762, 474-476.

Steiner, J., Bielau, H., Brisch, R., Danos, P., Ullrich, O., Mawrin, C., Bernstein H. G., and Bogerts, B. (2008). Immunological aspects in the neurobiology of suicide: elevated microglial density in schizophrenia and depression is associated with suicide. $J$. Psychiatr. Res. 42, 151-157.

Teismann, P., Tieu, K., Choi, D. K., Wu, D. C., Naini, A., Hunot, S., Vila, M., Jackson-Lewis, V., and Przedborski, S. (2003). Cyclooxygenase-2 is instrumental in Parkinson's disease neurodegeneration. Proc. Natl. Acad. Sci. U.S.A. 100, 5473-5478.

Tonelli, L. H., Stiller, J., Rujescu, D., Giegling, I., Schneider, B., Maurer, K., Schnabel, A., Möller, H. J., Chen, H.H., and Postolache, T. T. (2008). Elevated cytokine expression in the orbitofrontal cortex of victims of suicide. Acta Psychiatr. Scand. 117, 198-206.

Tsao, C. W., Lin, Y. S., Chen, C. C., Bai, C. H., and Wu, S. R. (2006). Cytokines and serotonin transporter in patients with major depression. Prog. Neuropsychopharmacol. Biol. Psychiatry 30, 899-905.

Tynan, R. J., Naicker, S., Hinwood, M., Nalivaiko, E., Buller, K. M., Pow, D. V., Day, T. A., and Walker, F. R. (2010). Chronic stress alters the density and morphology of microglia in a subset of stress-responsive brain regions. Brain Behav. Immun. doi: 10.1016/j. bbi.2010.02.001. [Epub ahead of print].

Watson, S., Horton, K., Bulmer, S., Carlile, J., Corcoran, C., Gallagher, P., and Ferrier, I. N. (2009). Effect of aspirin on hypothalamic-pituitary-adrenal function and on neuropsychological performance in healthy adults: a pilot study. Psychopharmacology 205, 151-155.

Webster, M. J., O'Grady, J., Kleinman, J. E., and Weickert, C. S. (2005). Glial fibrillary acidic protein mRNA levels 
in the cingulate cortex of individuals with depression, bipolar disorder and schizophrenia. Neuroscience 133 , 453-461.

Wheeler, R. D., and Owens, T. (2005). The changing face of cytokines in the brain: perspectives from EAE. Curr. Pharm. Des. 11, 1031-1037.

Wichers, M. C., and Maes, M. (2004). The role of indoleamine 2,3-dioxygenase (IDO) in the pathophysiology of interferon-alpha-induced depression. J. Psychiatr. Neurosci. 29, 11-17.
Wichers, M. C., Koek, G. H., Robaeys, G., Verkerk, R., Scharpe, S., and Maes, M. (2005). IDO and interferon-alphainduced depressive symptoms: a shift in hypothesis from tryptophan depletion to neurotoxicity. Mol. Psych. 10,538-544.

Yoshimura, R., Hori, H., Ikenouchi-Sugita, A., Umene-Nakano, W., Ueda, N., and Nakamura, J. (2009). Higher plasma interleukin-6 (IL-6) level is associated with SSRI- or SNRI-refractory depression. Prog. Neuropsychopharmacol. Biol. Psychiatry 33, 722-726.
Zaharia, M. D., Ravindran, A. V., Griffiths, J., Merali, Z., and Anisman, H. (2000). Lymphocyte proliferation among major depressive and dysthymic patients with typical or atypical features. J. Affect. Disord. $58,1-10$.

Conflict of Interest Statement: The author declares that the research was conducted in the absence of any commercial or financial relationships that could be construed as a potential conflict of interest.
Received: 07 January 2011; accepted: 31 March 2011;published online: 13 April 2011. Citation: Hayley S (2011) Toward an anti-inflammatory strategy for depression. Front. Behav. Neurosci. 5:19. doi: 10.3389/ fnbeh.2011.00019

Copyright $\odot 2011$ Hayley. This is an openaccess article subject to a non-exclusive license between the authors and Frontiers Media $S A$, which permits use, distribution and reproduction in other forums, provided the original authors and source are credited and other Frontiers conditions are complied with. 